\title{
ULTRASTRUCTURAL ANALYSIS OF FEMALE PACHYNEMA AND THE RELATIONSHIP BETWEEN SYNAPTONEMAL COMPLEX LENGTH AND CROSSING-OVER IN ZEA MAYS
}

by

\section{H. LLOYD MOGENSEN}

\author{
Department of Biological Sciences, Box 5640 \\ Northern Arizona University, Flagstaff, AZ 86001 \\ and \\ Department of Physiology, Carlsberg Laboratory ${ }^{1}$ ) \\ Gamle Carlsberg Vej 10, DK-2500 Copenhagen, Valby \\ 1) Visiting Professor 1976-77
}

\begin{abstract}
Keywords: Meiosis, maize, electron microscopy, three-dimensional reconstruction, crossing-over in male and female flowers
\end{abstract}

The synaptonemal complexes at pachynema of megasporocytes and microsporocytes in a single genotype of maize were reconstructed from electron micrographs of serial sections. The structure of the synaptonemal complexes, the structure of centromeres and knobs, the continuity of the synaptonemal complex through centromeres and interstitial knobs, centromere fusion, knob fusion and the mode and amount of telomere attachment to the nuclear envelope are consistent features of female and male meiocytes. The absence of large vacuoles within the nucleoli of megasporocytes is the most conspicuous difference between the two types of meiocytes. The mean total synaptonemal complex length of three female nuclei was $413 \mu \mathrm{m}$ and not significantly different from total bivalent length in reconstructed male nuclei. The size of female and male pachytene nuclei was likewise similar.

The plant studied carried a large terminal knob on the short arm of bivalent 9. According to RHOADES (42), the presence of this knob causes a sex difference in crossing-over in the short arm of bivalent 9 , reducing the female crossing-over value between the genes $C$ and $W x$. The female synaptonemal complex length of the short arm of chromosome 9 was found to be $66 \%$ of that of the male. No significant sex difference in synaptonemal complex length was detectable for the long arm of chromosome 9 or for chromosome 6 . It is proposed that the sex difference in crossing-over frequency is causally related to the difference in synaptonemal complex length. 


\section{INTRODUCTION}

Since its inception, the field of cytogenetics has relied heavily on the use of male meiocytes for structural analyses. This has been due to the greater accessibility and ease of handling of these cells in both plants and animals. Another reliance has been placed upon the assumption that meiosis is the same in both male and female meiocytes, and that the information and conclusions drawn from the male hold equally well for the female.

Although there is no reason at present to doubt this basic assumption, the fact remains that no fully detailed and comprehensive study has been made of female meiosis using modern techniques. Those studies which have been done on female meiosis in plants have been concerned mostly with megasporogenesis and embryo sac development at the light microscope level (9), or with cytoplasmic organelles and membrane systems at the electron microscope level $(11,26,43)$. Consequently, with the exception of investigations like those on Lilium and Fritillaria (13), Tulbaghia (47), barley and rye $(1,2,8)$, the limited studies which have been done, offer little information on chromosome structure and behaviour in the female meiocyte. Thus, a clear need exists for additional structural analyses of female meiosis using three-dimensional reconstructions from electron micrographs of serial sections. The pachynema of Zea mays was chosen in order to allow direct comparison with the study on male meiocytes by GILLIES (15).

Sex differences in recombination have been reported for several chromosome segments in maize (42). RHOADES (42) discovered that the presence and size of a terminal knob on chromosome 9 determine the sex difference in crossing-over in the adjacent chromosome region. The presence of a knob reduces the frequency of recombination in the short arm of chromosome 9 in female flowers but has no effect in male flowers. In its absence crossingover is equally frequent on the male and female side. Increased crossing-over frequencies are caused by the knob on chromosome 10 (K 10) and were found by GiLlies et al. (19) to be correlated with increased synaptonemal complex lengths. It was therefore reasoned that the sex difference in recombination determined by the knob on chromosome 9 may be reflected by differences in synaptonemal complex lengths.

\section{MATERIALS AND METHODS}

\subsection{Genetic Stocks}

Kernels for this study were generously provided by Professor M. M. RHOADES of Indiana University. The cross

$\frac{K^{L} Y g \operatorname{csh} w x}{w d c \operatorname{sh} w x}\left(33012\right.$ (5)) $\times \frac{K^{L} Y g c \operatorname{sh} w x}{w d C \operatorname{Sh} w_{x}}$ (33011(2))

yields four classes of genotypes. All are heterozygous for the $\mathrm{C}, \mathrm{Sh}$, and $\mathrm{Wx}$ loci which are located in the distal half of the short arm of chromosome 9. Class $\mathrm{I}$ is homozygous for a large terminal knob $\left(\mathrm{K}^{\mathrm{L}}\right)$ on the short arm. Class II is homozygous knobless. Classes III and IV are both heterozygous for the large knob, but differ in the linkage phase of the knob with the marker genes (see RHOADES (42) for further details on the progeny).

The homozygous knobless class II individuals are albino seedlings (homozygous wd) or greenwhite striped seedlings (homozygous wd and containing the Wd ring chromosome). These plants were not studied. The green seedlings comprising the other three classes were grown and sampled. It was not possible by electron microscopic analyses of pachytene cells to distinguish between the plants homozygous for the large terminal knob on the short arm of chromosome 9 (class I) and those heterozygous for the knob (class III and IV). The data obtained by RHOADES (42) reveal a large sex difference in crossing-over for plants heterozygous for the knob and a substantial difference in plants homozygous for the knob. A comparison of the organization of the synaptonemal complexes in female and male meiocytes of one of the genotypes was undertaken, but it is not known, whether the plant was homozygous or heterozygous for the knob. 


\subsection{Growing of plants, collection, and processing of tissue}

The majority of the plants used for this study were grown from kernels planted in the campus greenhouse of Northern Arizona University, Flagstaff, Arizone in late July, 1975. Temperatures were not rigidly controlled, but reached a maximum of about $27^{\circ} \mathrm{C}$ during the day and a minimum of about $18^{\circ} \mathrm{C}$ during the night. Additional plants, from the same batch of kernels, were grown in the phytotron of the Royal College of Forestry, Stockholm, Sweden. Photoperiod was 18 hours and the temperature $20^{\circ} \mathrm{C}$ during the day and $15^{\circ} \mathrm{C}$ at night.

Realizing that the genetic backgrounds of the maize strain used in the present study and those of GiLliEs (15) differed, collections of both male and female meiocytes were made.

To collect male flowers, a longitudinal slit was cut along the side of the plant to gain access to the young tassel. Plants approximately 60 days old usually contained staminate flowers in the proper stage of development (pachytene). This was determined by making acetocarmine squashes of one anther of a floret; subsequently, the other two were processed for electron microscopy.

After removal of a tassel primordium, the slit was taped and the female inflorescences were allowed to develop. This usually took from one to two weeks. At this time it was necessary to sacrifice the plant in order to remove the young ears which were usually still unemerged from the leaf axils. According to KIESSELBACH (28), female meiosis occurs when the silk is only a few millimeters long. Since aceto-carmine squashing was unsuccessful as a technique for stage determination in the females, collections were made of ear primordia possessing flowers with silk lengths ranging from zero to several centimeters.

Ear primordia were cut longitudinally into strips so as to separate each row of young pistillate flowers from the other; otherwise, the floral primordia were left attached to the axis of the inflorescence through the fixation period, after which they were separated individually. Leaving the floral primordia thus attached, aided in keeping them submerged during fixation.
In all, collections of anthers were made from 14 plants, and from seven of these, ovaries were also collected. All tissue was first fixed in $4 \%$ glutaraldehyde $(0.1 \mathrm{M}$-sodium cacodylate buffer, $\mathrm{pH} 7.2$ ) for 3 to 5 hours at room temperature. Subsequently, one half of the material was postfixed in $1 \%$ osmium tetroxide (same buffer) for 2 hours at $4^{\circ} \mathrm{C}$, rinsed 3 times in buffer, then dehydrated in a graded series of ethanol and transferred to absolute acetone before infiltration with an epon-araldite mixture (20). The rest of the material was not postfixed in osmium, but was otherwise processed as just described except for the last change of absolute ethanol which contained $1 \%$ phosphotungstic acid (PTA). Staining times in PTA were $12,13,14,15$, or 17 hours at $4^{\circ} \mathrm{C}(44)$.

\subsection{Serial sectioning, reconstruction, and orien- tation of tissue}

Serial sectioning and three-dimensional reconstruction were carried out according to the method used by GILLIES (15), except that once the tracings were made on the plastic sheets, absolute lengths of the synaptonemal complexes were determined using a Hewlett Packard digitizer (HP9864A) and calculator (HP9825A).

Since each ovary contains only one megasporocyte, orientation and approach to this cell become critical steps in the serial sectioning technique. After using thick sections and light microscopy to determine that silk length which corresponds to the pachytene stage (usually about $2 \mathrm{~mm}$, but this varies for each plant), the female floret was trimmed parallel to line $A B$ as shown in Figure 1. Upon reaching the locule, sections $2 \mu \mathrm{m}$ in thickness were taken until a distance of about $6 \mu \mathrm{m}$ into the megasporocyte was reached (Fig. 2). At this point, the block face was final-trimmed and ultra-thin sectioning was carried out as described by Gulles (15). Final identification of the pachytene stage was based upon the presence of the intact synaptonemal complex along the entire length of all bivalents.

Since GILLIES (15) had found that tracing of the synaptonemal complex was facilitated by positive staining with alcoholic PTA, this was 


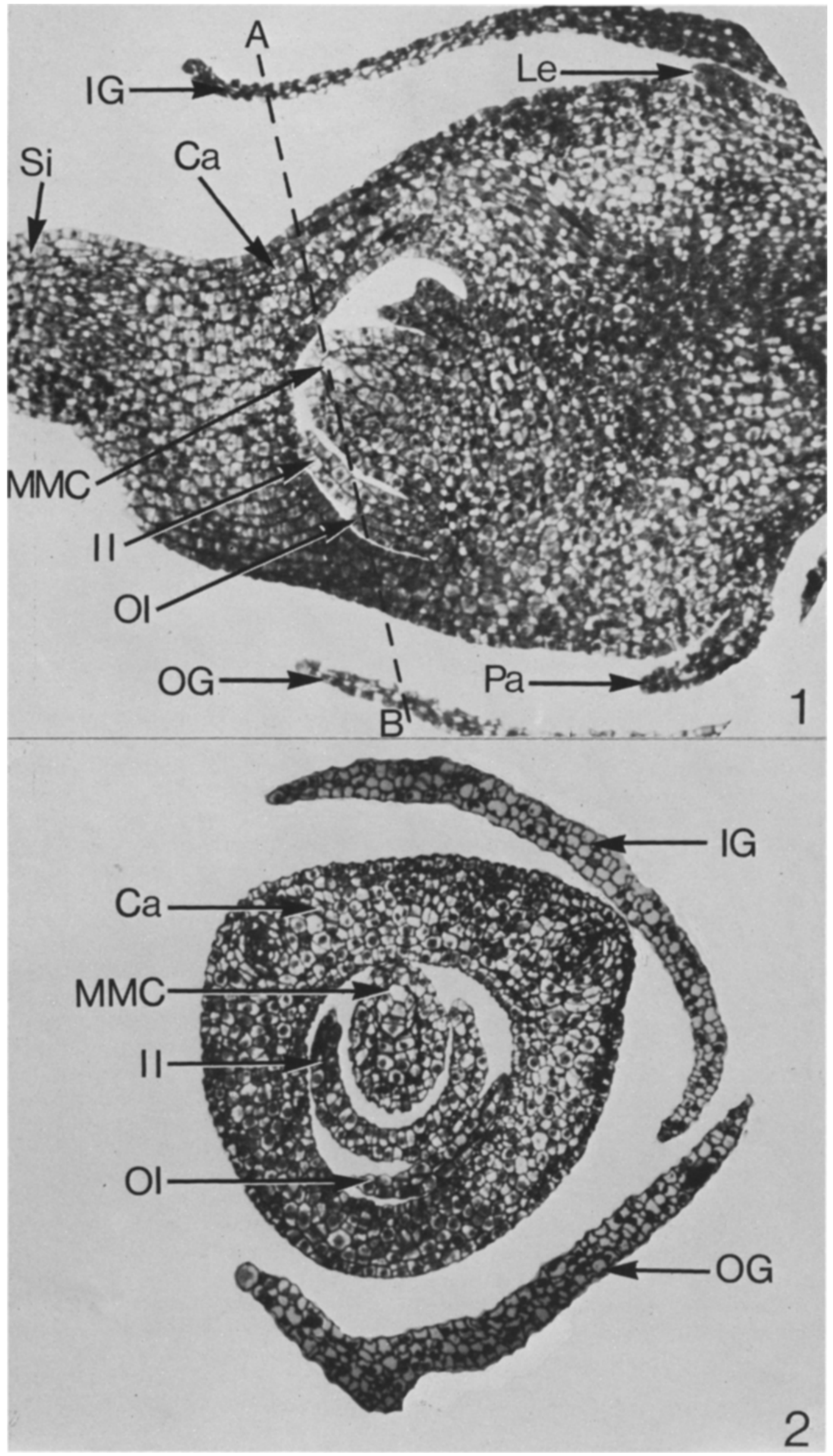


Figure 1. Median logitudinal section of pistillate flower and megaspore mother cell (MMC). Trimming and thick sectioning is done parallel and up to line $\mathrm{AB}$ before ultra-thin sectioning is begun. $\mathrm{Ca}$, carpel; IG, inner glume; II, inner integument; Le, lemma; OG, outer glume; 01, outer integument; Pa, palea; Si, silk. $200 \mathrm{x}$

Figure 2. Transverse section of pistillate flower and megaspore mother cell at level of line AB in Fig. 1. Labels are the same as in Fig. 1.200x

the first approach used in this study. However, the initial staining time used (17 hours) was found to be too long, thus the lateral components of the synaptonemal complex were stained not unlike the surrounding chromatin. Moreover, when shorter staining times were tried with material grown in Stockholm, it was found that those times (13 to 15 hours) which stained the lateral components and not the chromatin were also undesirable because the nuclei were extremely difficult to view in the electron microscope during picture taking.

Consequently, only one PTA nucleus (cell II, Tables I and II) was reconstructed. Next, an osmium-fixed nucleus, whose sections were poststained with lead citrate and uranyl acetate, was reconstructed, but only with great difficulty and the consumption of an inordinate amount of time. Form these preliminary data it was clear that synaptonemal complex length for the entire genome of the female meiocyte (373.4 $\mu \mathrm{m}$ and $422.0 \mu \mathrm{m})$ did not differ significantly form that of GiLLIEs' male (mean synaptonemal complex length for five nuclei $=353.2 \mu \mathrm{m}$ ). Therefore, a male nucleus from the present study's collections was reconstructed (cell I, Table I). Finding the total synaptonemal complex length $(448.8 \mu \mathrm{m})$ to be somewhat longer than that of the female (though still not significantly longer) prompted the analysis of both male and female meiocytes for this study, and led to the realization that if a sex difference in synaptonemal complex length did exist, it probably was at the individual bivalent level.

In an attempt to reduce the number of sections required to pass through a nucleus (and consequently reduce the amount of time and materials for reconstruction), sections were cut at varying thickness levels above the usual 800 A. It was found that sections of about $1500 \AA$ were very useable even when operating the electron microscope at $80 \mathrm{KV}$, and that, in most cases, visibility of the synaptonemal complex was enhanced (Figs. 4, 8, 10-13). This was especially true for those portions of the bivalents which were in transverse section; an orientation that is often difficult to follow with the thinner sectioned material.

A total of 10 female and 6 male meiocytes were serially sectioned. But, due to the loss of sections, ambiguity resulting from knob fusion, excessive intermingling of bivalents, etc., or rejection because of an incorrect stage, the results being reported here are based upon reconstructions of only 6 male and 5 female nuclei. Section thickness, fixation, etc. for each nucleus is listed in Tables I and II. Electron micrographs were taken at a primary magnification of 3,000 X using a Siemens 102 electron microscope. This image was then printed approximately 4.5 times larger.

Since length differences (if any) were now thought to be at the level of the bivalent, in most cases, only bivalent 6 (which is attached to the nucleolus) and bivalent 9 (which is the only one having a large knob on the short arm) were reconstructed because they can be unequivocally identified. Reconstructions of the other bivalents were not considered pertinent because of the likelihood of misclassification when they are identified by relative lengths only.

All meiocytes used for this investigation came from the same plant. The ear primordium was the second from uppermost on the plant, and the silk lengths ranged from $0.0 \mathrm{~mm}$ to 2.75 $\mathrm{mm}$. All microsporocytes were contained in the same anther.

\section{RESULTS}

\subsection{Megasporocyte}

The megasporocyte at pachynema is an elongated cell approximately $45 \mu \mathrm{m}$ by $18 \mu \mathrm{m}$ located near the micropylar apex of the young nucellus (Figs. 1 and 2). The nucleus is 


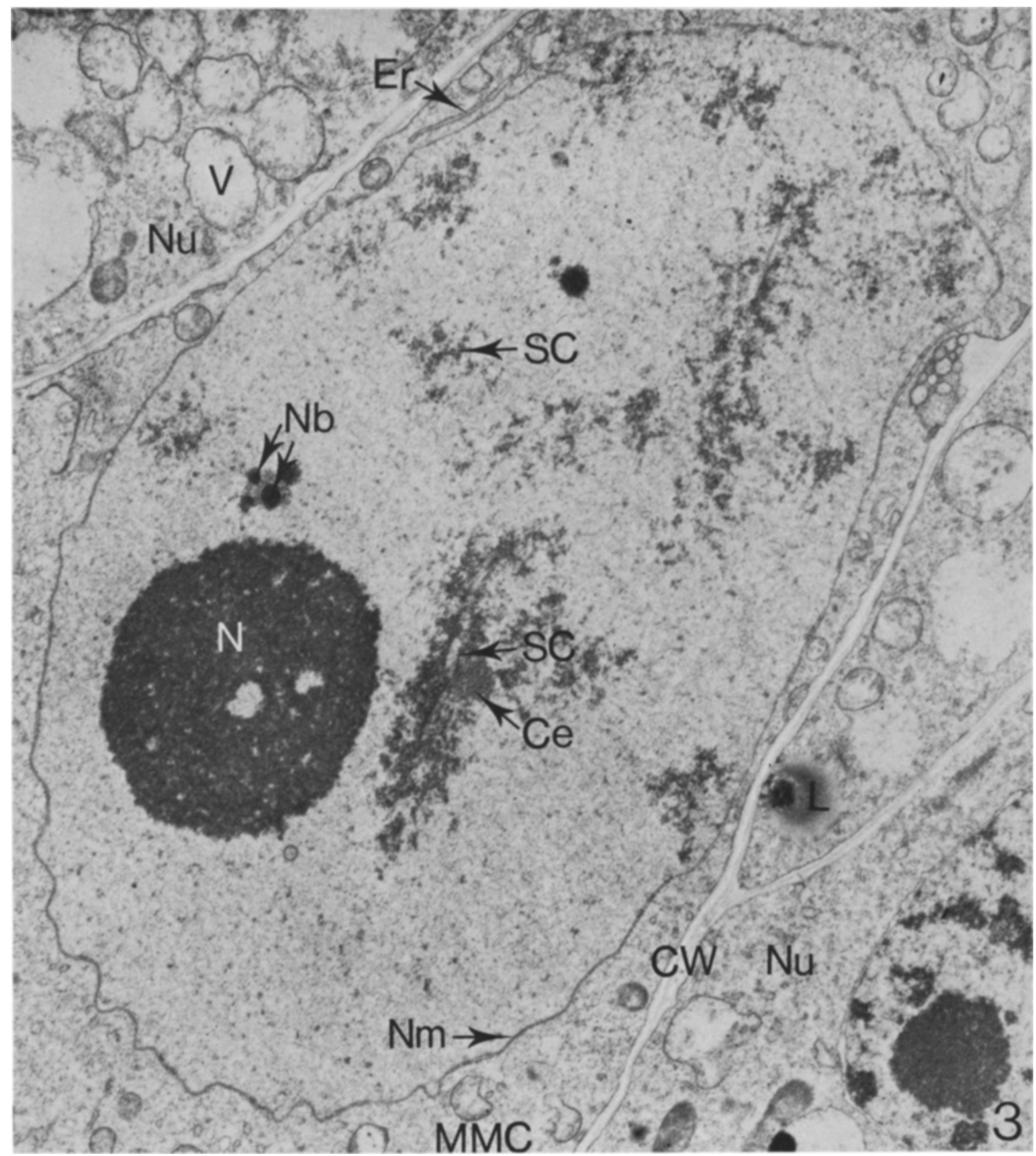

Figure 3. Survey picture of megasporocyte (MMC) nucleus at pachynema, sectioned at $800 \mathrm{~A}$. Ce, centromere; $\mathrm{CW}$, cell wall; $\mathrm{Er}$, endoplasmic reticulum; $\mathrm{L}$, lipid body; $\mathrm{N}$, nucleolus; $\mathrm{Nb}$, nuclear bodies; $\mathrm{Nm}$, nuclear membrane; $\mathrm{Nu}$, nucellus; $\mathrm{SC}$, synaptonemal complex; V, vacuole. 13,000 $\times$

Figure 4. Survey picture of megasporocyte (MMC) nucleus at pachynema, sectioned at $1500 \AA$. D, dictyosome; $\mathrm{CW}$, cell wall, Er, endoplasmic reticulum; L, lipid body; N, nucleolus; Nm, nuclear membrane; Nu, nucellus; Sc, synaptonemal complex; $V$, vacuole. $9,750 \times$ 


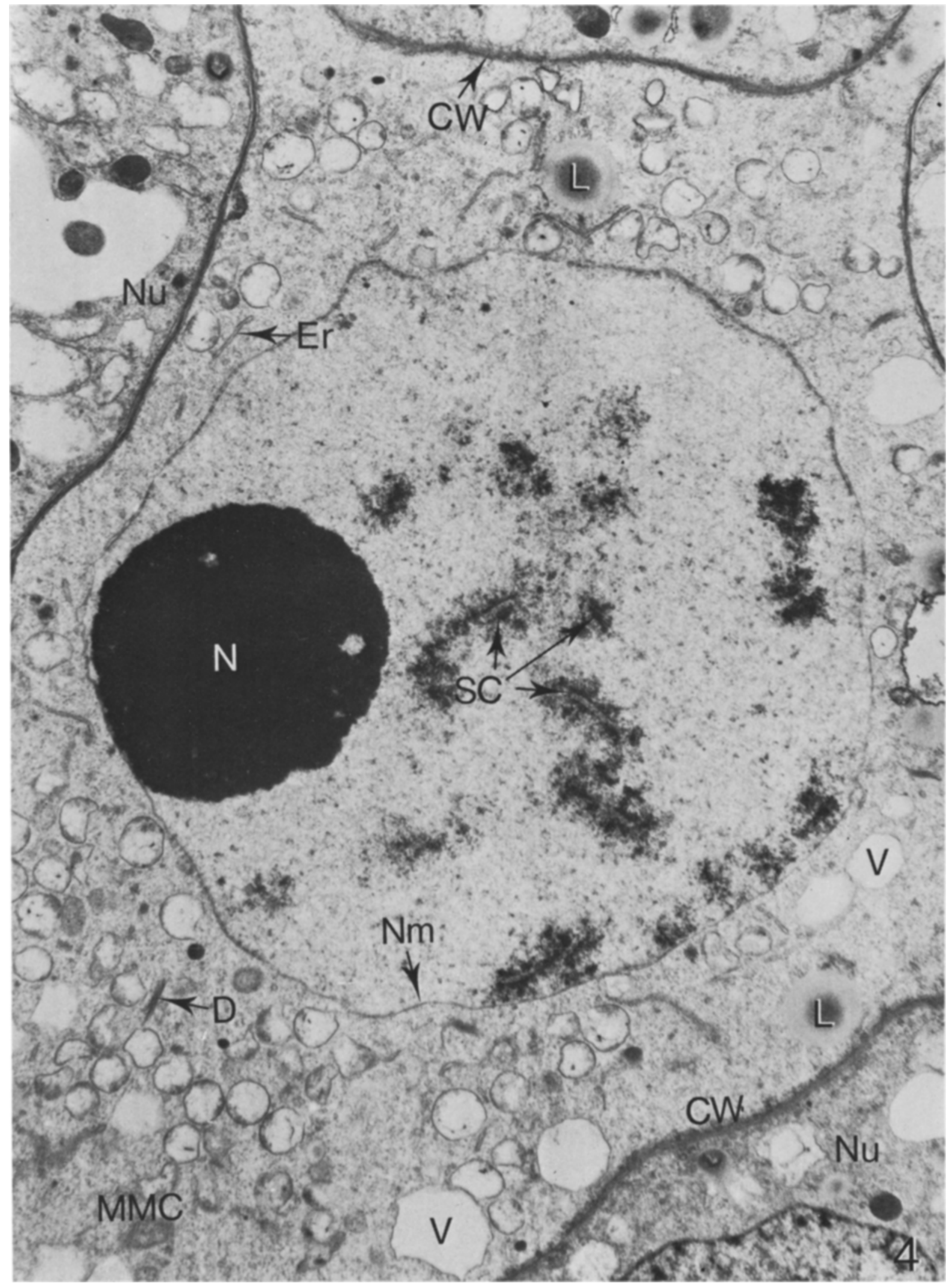


Table I.

Data on synaptonemal complex of bivalent 9 in plant No. 6 .

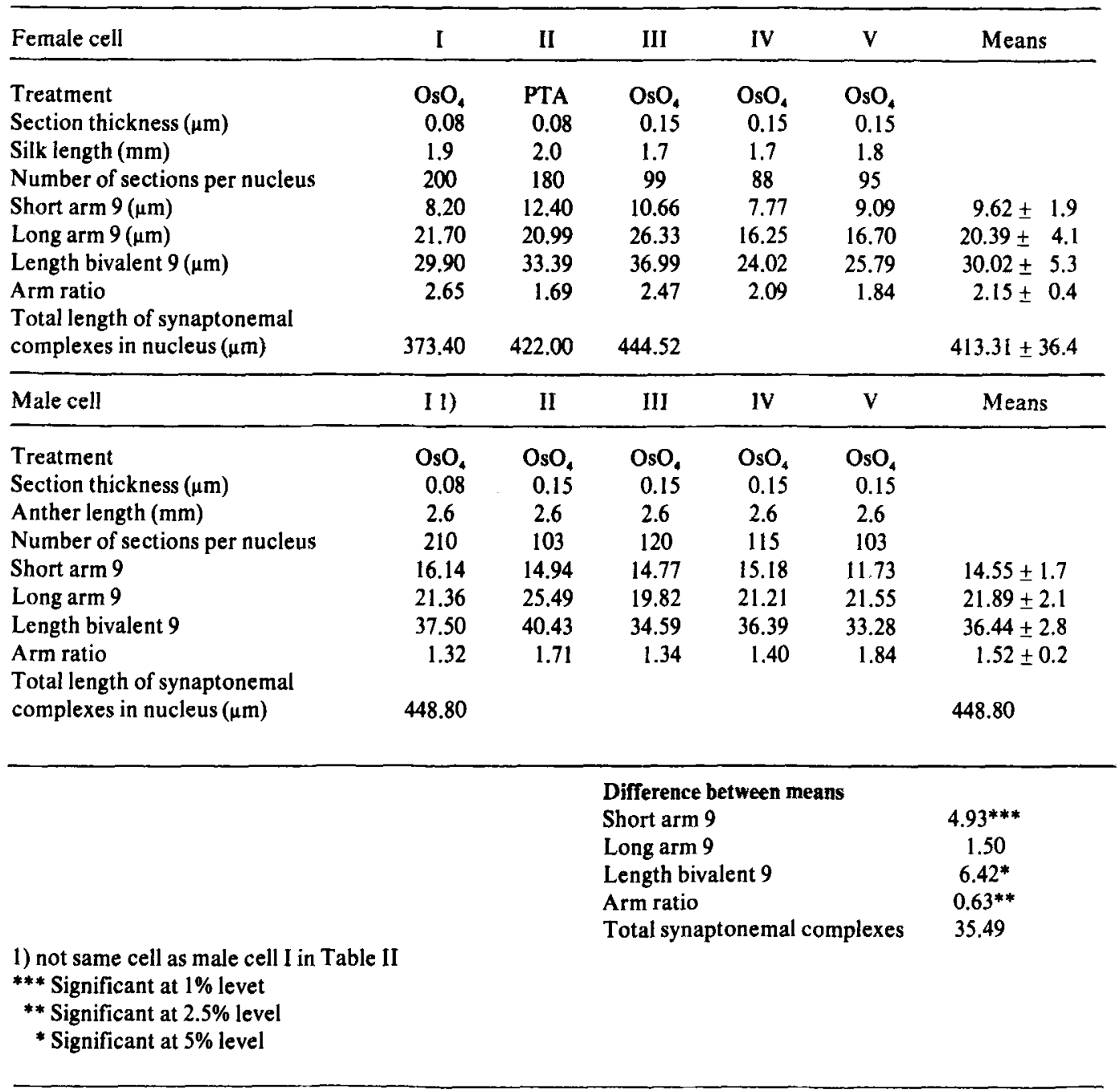

positioned toward the chalazal end of the meiocyte and is surrounded by cytoplasm containing lipid bodies, short stretches of lamellate endoplasmic reticulum, occasional dictyosomes, small vacuoles, and numerous doublemembrane organnelles. The latter are undoubtedly plastids and mitochondria, but their presumably dedifferentiated condition (11) does not allow for an unequivocal distinction between the two (Figs. 3 and 4). Ribosomes are abundant, but usually of less frequency than in the surrounding nucellar cells (Figs. 3, 4, and 9).

The homologous chromosomes are fully synapsed via the synaptonemal complex which has a typical morphology $(17,48)$. The electron opaque lateral components are approximately $400 \AA$ in width separated by an electron translucent central region about $1000 \AA$ in diameter. Within the central region is located a central component of medium density having a diameter of approximately $500 \AA$ (Figs. 5 to 9). The synaptonemal complex is surrounded by chromatin fibrils which are in varying degrees of compaction along the length of the bivalent (Figs. 3 to 9). The familiar twisting nature of the pachytene bivalent as seen with the light microscope (40) is reflected in the synaptonemal complex (Fig. 9). Upon occasion, 
Table II

Data on synaptonemal complex of bivalent 6 in plant No. 6 .

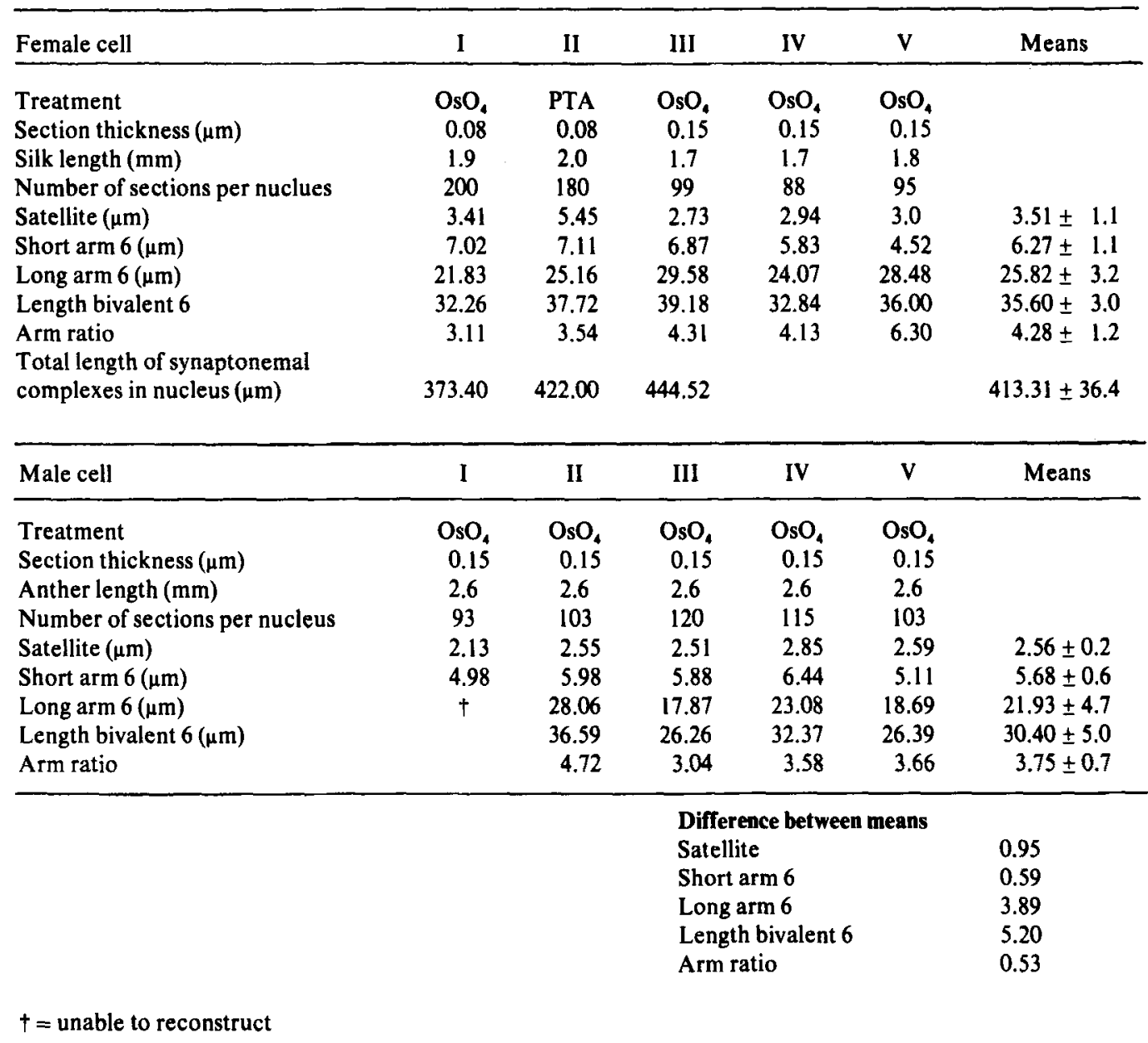

localized modifications of the central component into what have been termed nodules (17, 48, 50) were seen (Fig. 7, inset). However, no thickenings or splitting of the lateral components were observed such as reported by GiLliEs (15) for the male.

The centromere is readily distinguishable from other chromatin regions by being more spherical and less electron opaque than knobs or chromomeres. Also, the filamentous substructure of the centromere appears less coarse, probably due to the absence of beaded nucleosomes. The synaptonemal complex passes uninterrupted and without structural modification through the centromere (Figs. 3, 6 and 7). Confirmation of centromere identity was gained by finding ten centromeres per nucleus, one for each bivalent, as well as by agreement of expected arm ratios with those published by Gillies (15) and RHOADES (40). The fusion of centromeres with centromeres, and knobs with knobs was commonly observed (Figs. 7 and 9). A close association of knobs with the nuclear membrane was also of common occurrence (Fig. 9).

In nearly all casses, at least one telomere of a bivalent was closely associated with the nuclear membrane; however, in no case, was the syn- 
Table III

Length of the synaptonemal complexes of female cell III.

\begin{tabular}{c|c|c|c|c}
\hline Bivalent & Total $(\mu \mathrm{mn})$ & Long Arm $(\mu \mathrm{m})$ & Short arm $(\mu \mathrm{m})$ & Arm Ratio \\
\hline 1 & 61.76 & 41.28 & 20.48 & 2.02 \\
2 & 59.23 & 30.56 & 28.67 & 1.07 \\
3 & 53.36 & 37.34 & 16.02 & 2.33 \\
4 & 50.75 & 34.11 & 16.64 & 2.05 \\
5 & 46.02 & 26.22 & 19.80 & 1.32 \\
6 & 39.18 & 29.58 & $6.87^{*}$ & 4.31 \\
7 & 38.25 & 27.83 & 10.42 & 2.67 \\
8 & 32.46 & 22.54 & 9.92 & 2.27 \\
9 & 36.99 & 26.33 & 10.66 & 2.47 \\
10 & 26.52 & 19.81 & 6.71 & 2.95 \\
& 444.52 & & & \\
\hline
\end{tabular}

* Short arm length of bivalent 6 does not include satellite $(2.73 \mu \mathrm{m})$ or gap $(1.0 \mu \mathrm{m})$ in nucleolus organizer region.

aptonemal complex directly attached to the nuclear membrane. Rather, the lateral components and cental region terminate a short distance away; i.e. to within 500 to $1000 \AA$ (Figs, 8 and 9). From the example shown in Fig. 19 (which was taken from female cell III of Tables I and II), it can be seen that, in this case, all but two bivalents have at least one telomere "attached" to the nuclear membrane; two bivalents ( 3 and 7) have neither telomere attached and two bivalents ( 6 and 10 ) have both telomeres attached. This nucleus (Figs. 18 and 19) also illustrates the tendency for the bivalents to remain in the bouquet stage even though all chromosomes are fully synapsed. Figures 20 and 21 illustrate the nuclear pore distribution for this nucleus. By comparison with Figure 19, it can be seen that the pores tend to be located away from the general area of telomere attachment, as well as away from the nucleolus. An idiogram of all ten bivalents from this female nucleus (cell III) is shown in Figure 23 and Table III,

Reconstructions of bivalent 6 yielded values for synaptonemal complex length and arm ratio (Table II and Fig. 15) which are in agreement with the published karyotypes (15). However, the consistent "gap" in the synaptonemal complex within the nucleolus organizer (Figs. 10 to 13, and 15) differs from the findings of GILLIES (15) for microsporocytes presumably in mid pachynema. The occurrence of a small terminal knob on the satellite of bivalent 6 was consistent in all nuclei, but small knobs on the long arm were only present in some cases (Fig. 22).

Bivalent 9 (Table I, and Fig. 17) was found to have a mean synaptonemal complex length of $30.02 \mu \mathrm{m}$ which is similar to the $28.1 \mu \mathrm{m}$ reported by GiLliEs (15) for bivalent 9 in the microsporocytes of the genotypes studied by

Figure 5. Longitudinal and transverse sections of bivalents showing the synaptonemal complex (SC) with its lateral components (LC) and the central region with its central component (CC). The surrounding chromatin is evident. $32,500 \times$

Figure 6. Longitudinal section through the centromere (Ce) showing the continuity of the synaptonemal complex (SC) in this region. $\mathrm{Nm}$, nuclear membrane. $26,000 \times$

Figure 7. Longitudinal and transverse views of two bivalents with fused centromeres $(\mathrm{Ce})$. Nm, nuclear membrane. $26,000 \times$. Inset shows localized modifications (No, nodule) of the central component. 65,000 $\times$ 







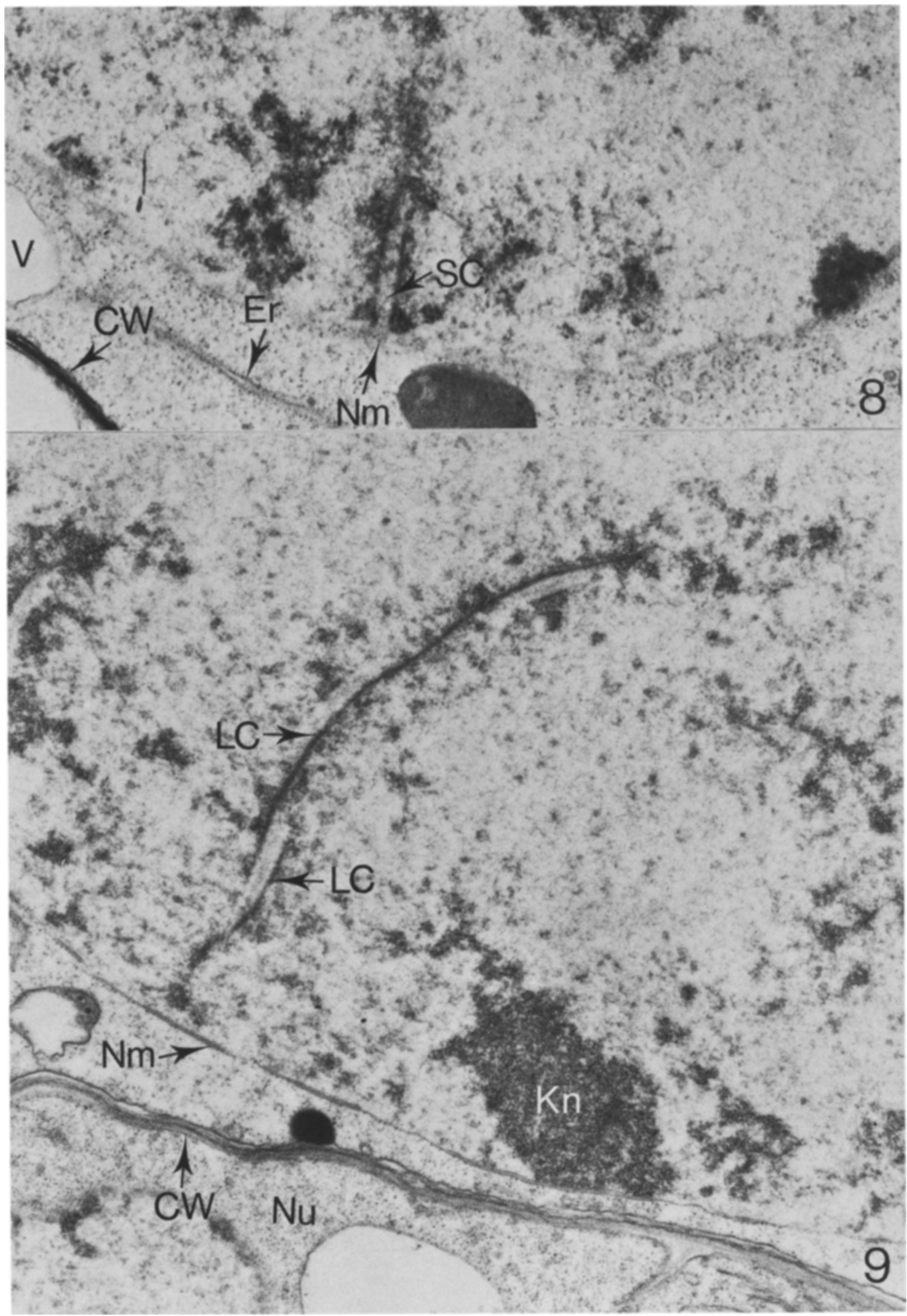


Figure 8. Fifteen hundred $\AA$ section showing association of a telomere to the nuclear membrane (Nm). Note that neither the chromatin or the synaptonemal complex (SC) is actually in contact with the membrane. $\mathrm{CW}$, cell wall; Er, endoplasmic reticulum; V, vacuole. $26,000 \times$

Figure 9. Longitudinal view of the synaptonemal complex showing its twisted nature. $\mathrm{CW}$, cell wall; $\mathrm{Kn}$, $\mathrm{knob}$; LC, lateral component; $\mathrm{Nm}$, nuclear membrane; $\mathrm{Nu}$, nucellus. $26,000 \times$

him. The mean arm ratios were also in good agreement; that of the present study being 2.15 compared to 1.89 in (15). As with bivalent 6 , the presence of knobs is variable, except for the large terminal knob on the short arm of bivalent 9 which was present in all nuclei (Fig. 22). Knob variability at the electron microscope level has also been reported by GILLIES (15) for maize and by HOLM and RASMUSSEN (24) for the human male.

The nucleolus of all megasporocytes examined in the present study consisted of a central fibrillar area surrounded by a peripheral granular zone (Figs. 3, 4, and 14). Occasionally small vacuoles were present, but in no case was a large central vacoule found such as is typical in microsporocytes (present study and 15). Megasporocyte nucleoli of the stock used in the present study appear to lack any kind of inclusions such as the "hollow dark bodies" or "fusiform striated bodies" reported by GiLLIES and HYDE (18). However, small groups of dense electron opaque "nuclear bodies" (15) were frequently seen (Fig. 3).

\subsection{Microsporocyte}

Morphological observations made in the present study on male meiocytes at pachynema agree with those of GILLIES (15) in all respects, save three exceptions. No nucleolar inclusions were observed, no modifications of the lateral components were seen, and in all cases, a distinct gap with a mean length of $1.08 \mu \mathrm{m}$ (range $=0.70-1.51 \mu \mathrm{m}$ ) was present in the synaptonemal complex in the nucleolus organizer region of bivalent 6 .

Measurements (Tables I and II) show that the mean synaptonemal complex length of 30.40 $\mu \mathrm{m}$ for bivalent 6 is similar to the $32.6 \mu \mathrm{m}$ reported by GiLlies (15) in his material. Although the mean synaptonemal complex length of this bivalent is longer on the female side, the difference was not statistically significant (Table II). The mean length of bivalent 9 in the present study $(36.4 \mu \mathrm{m})$ is greater than the $28.1 \mu \mathrm{m}$ reported by GiLlies (15). A most intriguing result of the present study is the increased length of the synaptonemal complex of the short arm of chromosome 9 in the microsporocytes when compared with this arm in the megasporocytes of the same plant (Table I, Figs. 16, 17, and 22). On the other hand, no sex difference is encountered in the long arm of bivalent 9 . As a consequence, the arm ratio for this bivalent becomes significantly lower in the microsporocyte than in the megasporocyte. The sex difference in synaptonemal complex length of the short arm of bivalent 9 matches the sex difference in crossing-over frequencies obtained by RHOADES (42). The average male crossing-over value for the C-Wx region in this arm amounted to $28 \%$, the synaptonemal complex length of the arm was $14.55 \mu \mathrm{m}$. The female crossing-over value for the $\mathrm{C}$ - $\mathrm{Wx}$ region was found to be $22 \%$ in plants homozygous for the knob and between $9 \%$ and $17 \%$ in plants heterozygous for the knob. The synaptonemal complex length for the arm of the plant studied here was $9.62 \mu \mathrm{m}$. The female crossing-over value thus is lower than that of the male, and the female synaptonemal complex length is shorter than that of the male.

\section{DISCUSSION}

\subsection{Morphological features of male and female pachynema}

Morphologically, the pachytene stage of microsporocytes and megasporocytes of Zea mays is essentially similar. The make up and dimensions of the synaptonemal complex, the structure of centromeres and knobs, the continuity of the synaptonemal complex through 


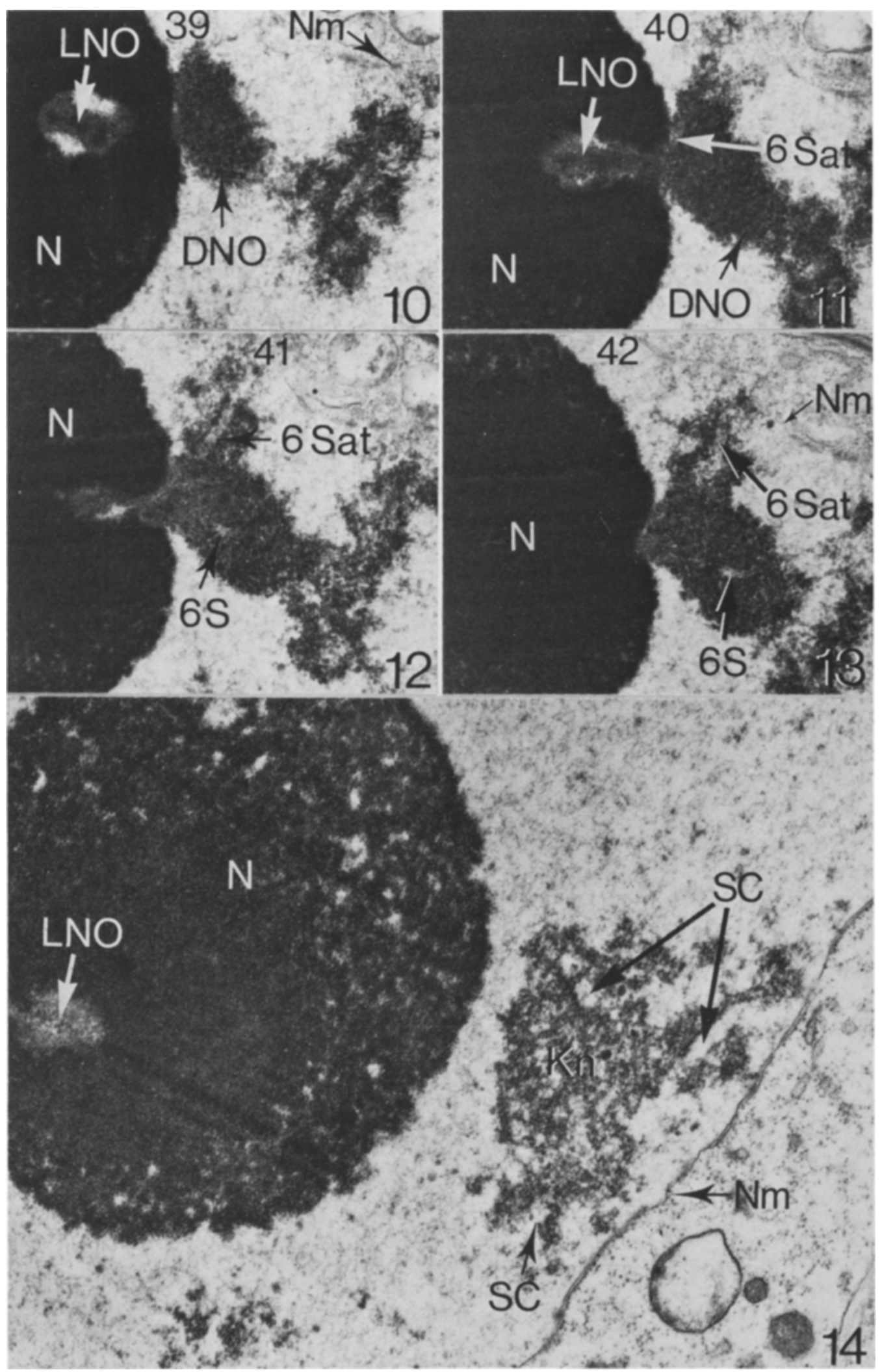


Figure $10,11,12$ and 13. Consecutive serial sections, cut at $1500 \AA$, through the gap region of the synaptonemal complex in the nucleolus organizer of bivalent 6 . These pictures are from sections $39,40,41$ and 42 .Diagram of total reconstruction is shown in Fig. 15. 6S, short arm of bivalent 6; 6 Sat, satellite of bivalent 6; DNO, dark nucleolus organizer; i.e. knob region; $\mathrm{LNO}$, light nucleolus organizer; $\mathrm{N}$, nucleolus; $\mathrm{Nm}$, nuclear membrane. all $15,600 \times$

Figure 14. Section through the nucleolus $(\mathrm{N})$ and fused knobs $(\mathrm{Kn})$ of different bivalents. The nucleolus was never seen to have large vacuoles as is common in microsporocytes. LNO, light nucleolus organizer; Nm, nuclear membrane; SC, synaptonemal complex. $25,600 \times$

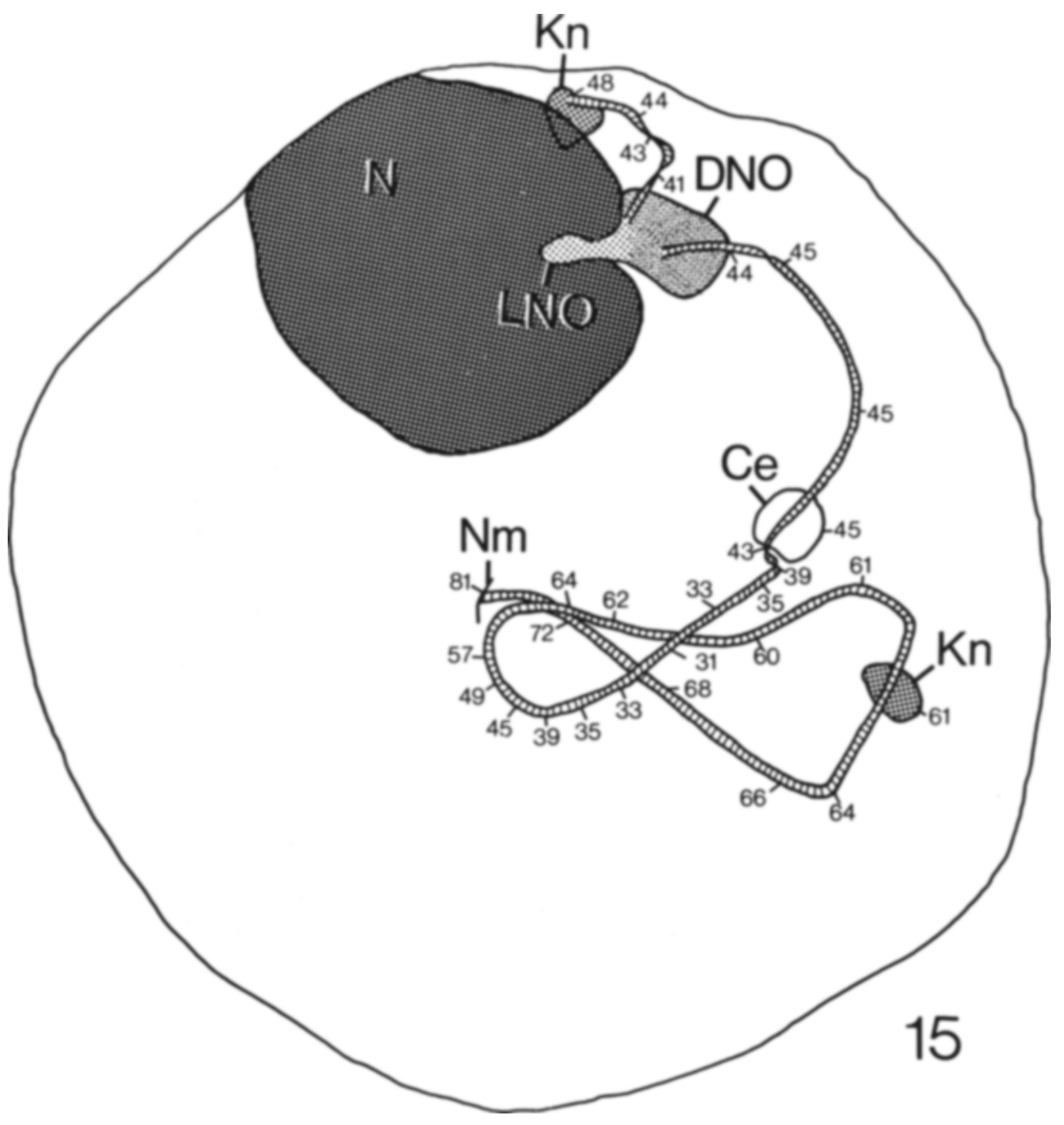

Figure 15. Reconstruction of the synaptonemal complex of bivalent 6 from cell IV female of Tabel II. Gap in the synaptonemal complex within the nucleolus organizer region is consistent for both male and female meiocytes of present study. Ce, centromere; DNO, dark nucleolar organizer; Kn, knob; LNO, light nucleolus organizer; N, nucleolus; $\mathrm{Nm}$, nuclear membrane. Numbers are section numbers. $15,600 \times$ 


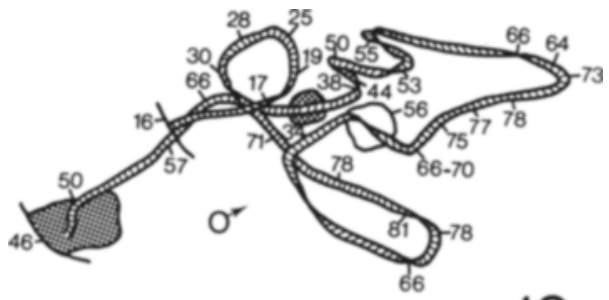

16

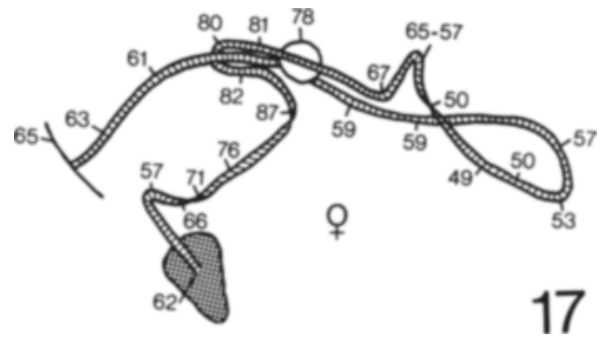

Figure 16. Reconstruction of synaptonemal complex of bivalent 9 from microsporocyte IV of Table I. Stippled areas are knobs, open circle is centromere. Perpendicular line at bivalent ends is nuclear membrane. Numbers are section numbers. $17,250 \times$

Figure 17. Reconstruction of synaptonemal complex of bivalent 9 from megasporocyte $V$ of Table I. Stippled area is a knob, open circle is centromere, perpendicular line at telomere is nuclear membrane. Numbers are section numbers. $17,250 \times$

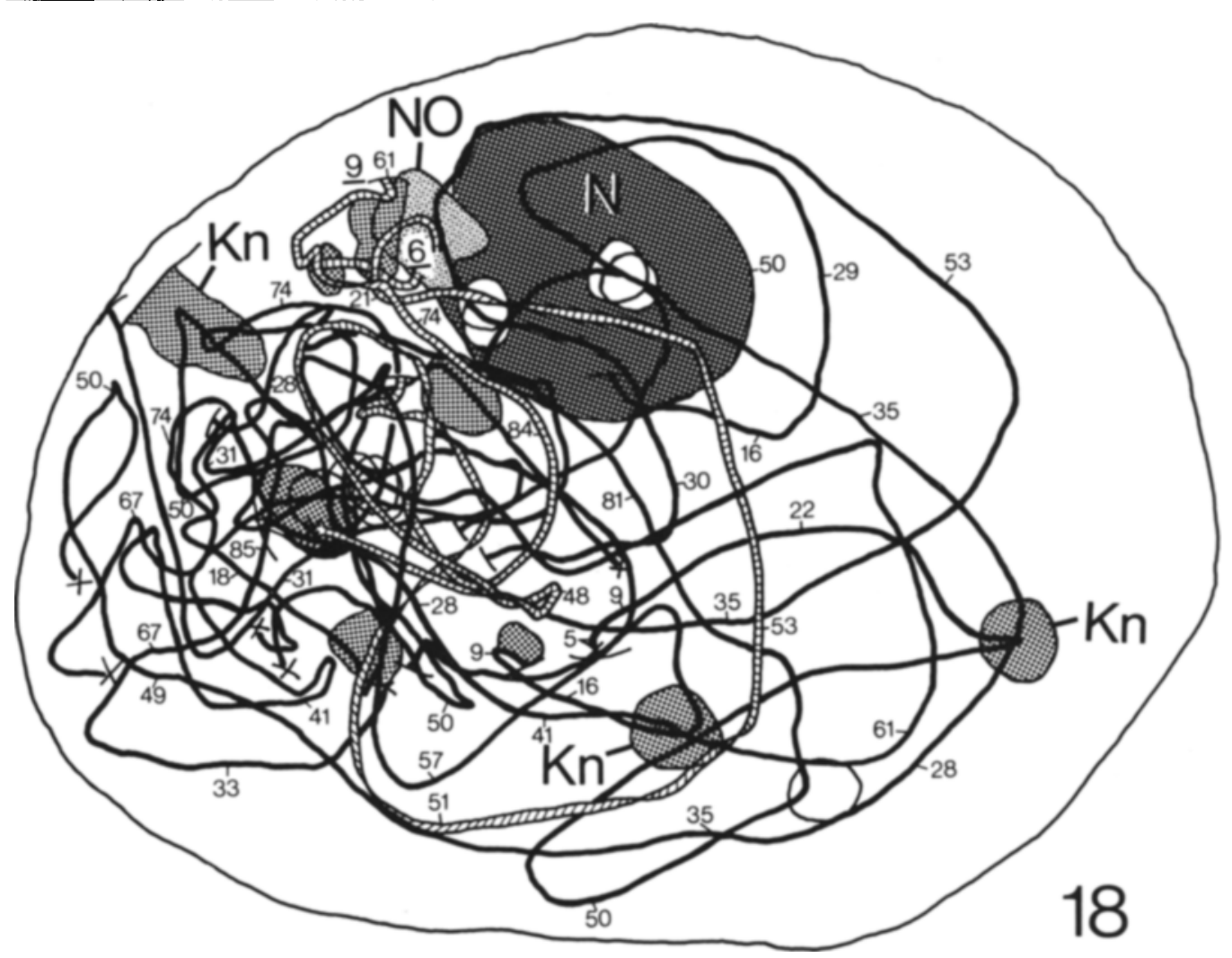

Figure 18. Reconstruction of synaptonemal complexes of all 10 bivalents of megasporocyte III of Tables I and II. $\mathrm{Kn}$, knobs; N, nucleolus; NO, nucleolus organizer. Open circles are centromeres. Small numbers are section numbers. Crosses $(X)$ at bivalent ends indicate no association with nuclear membrane. Bivalents 9 and 6 are indicated with large numbers, and open synaptonemal complex with cross lines. 12,860 $x$ 


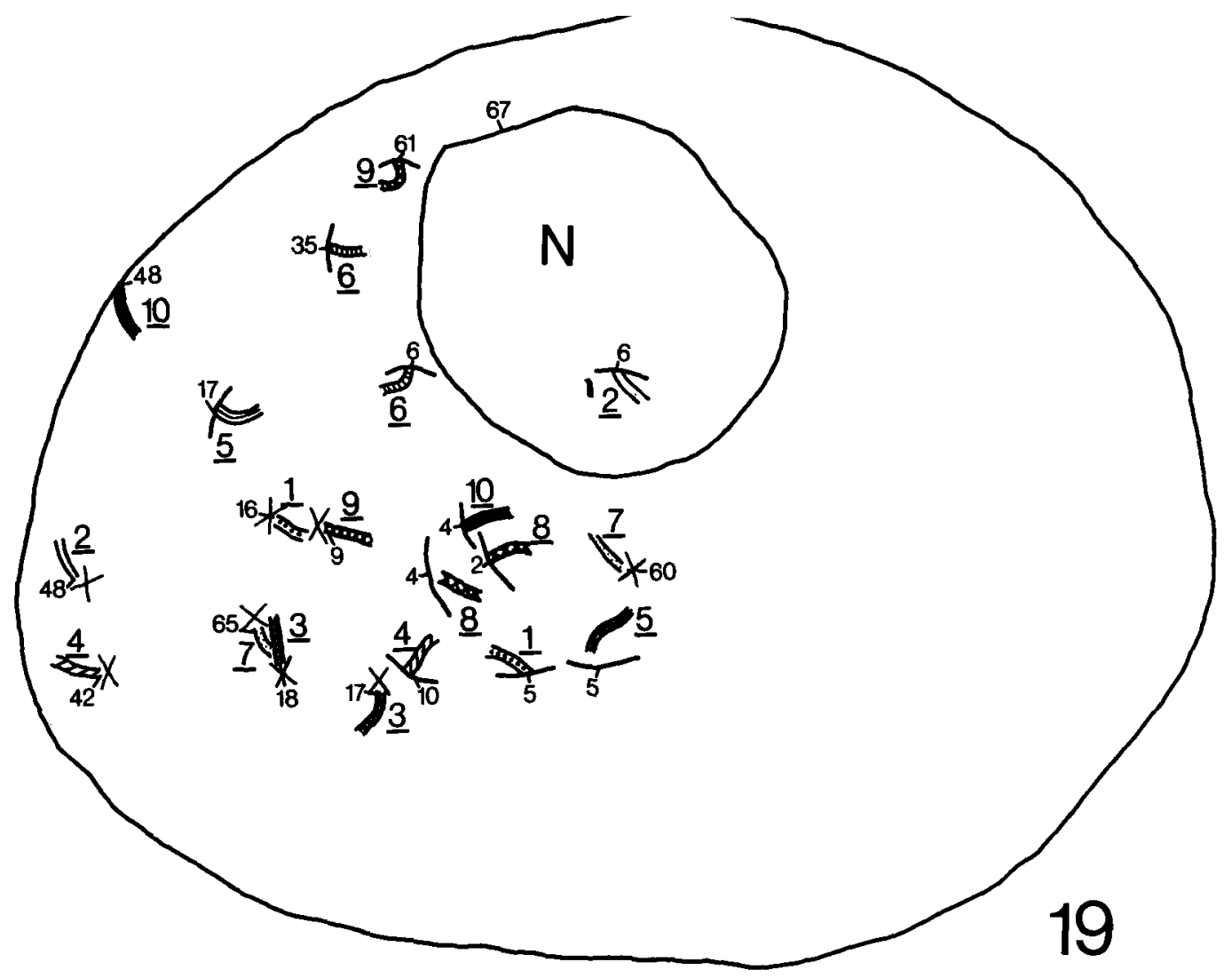

Figure 19. Location of bivalent ends from same cell as in Fig. 18. Large numbers are bivalent numbers, small numbers are section numbers. N, nucleolus. Perpendicular lines at or near bivalent ends represent nuclear membrane; crosses $(\mathrm{X})$ indicate no association of telomere with the nuclear membrane. $12,860 \times$

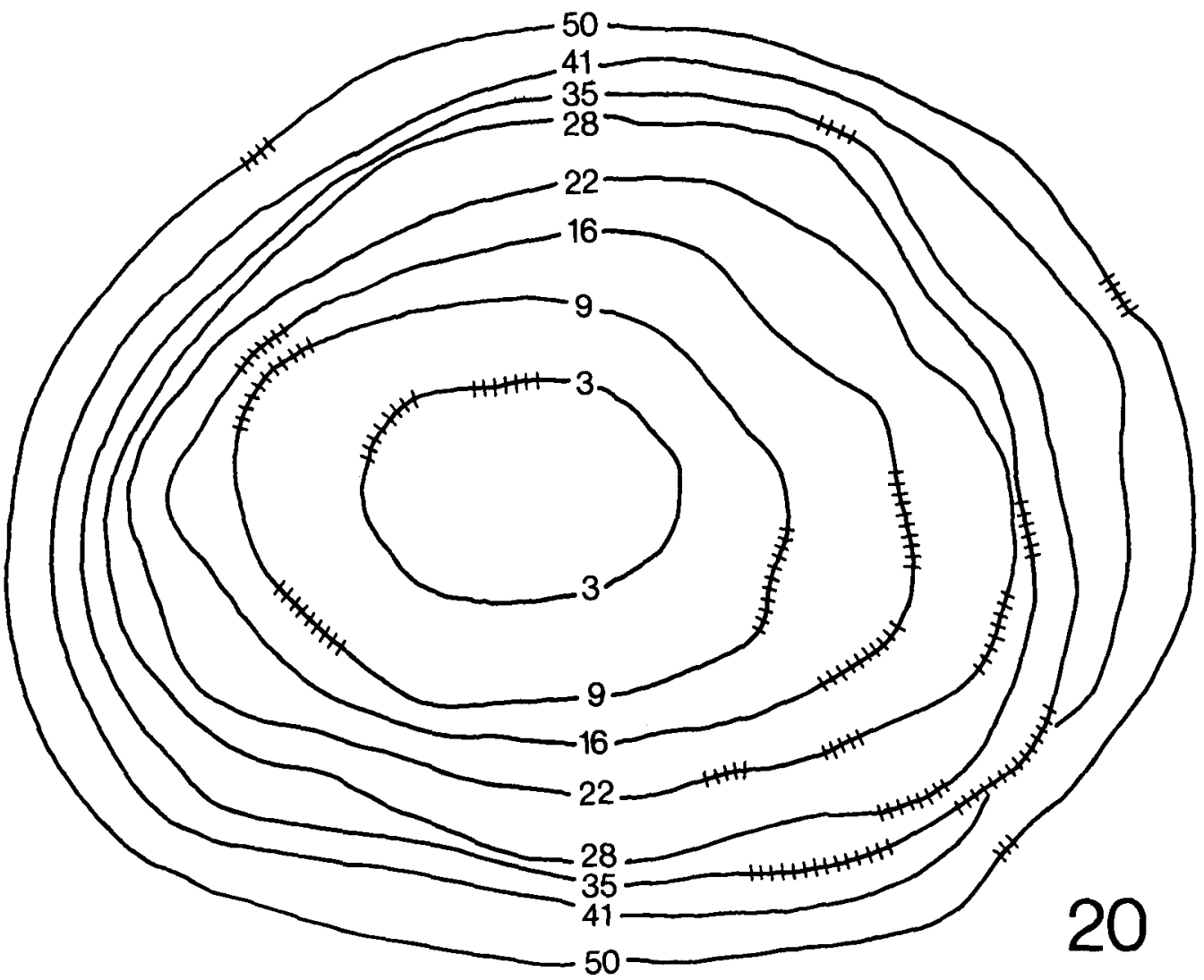




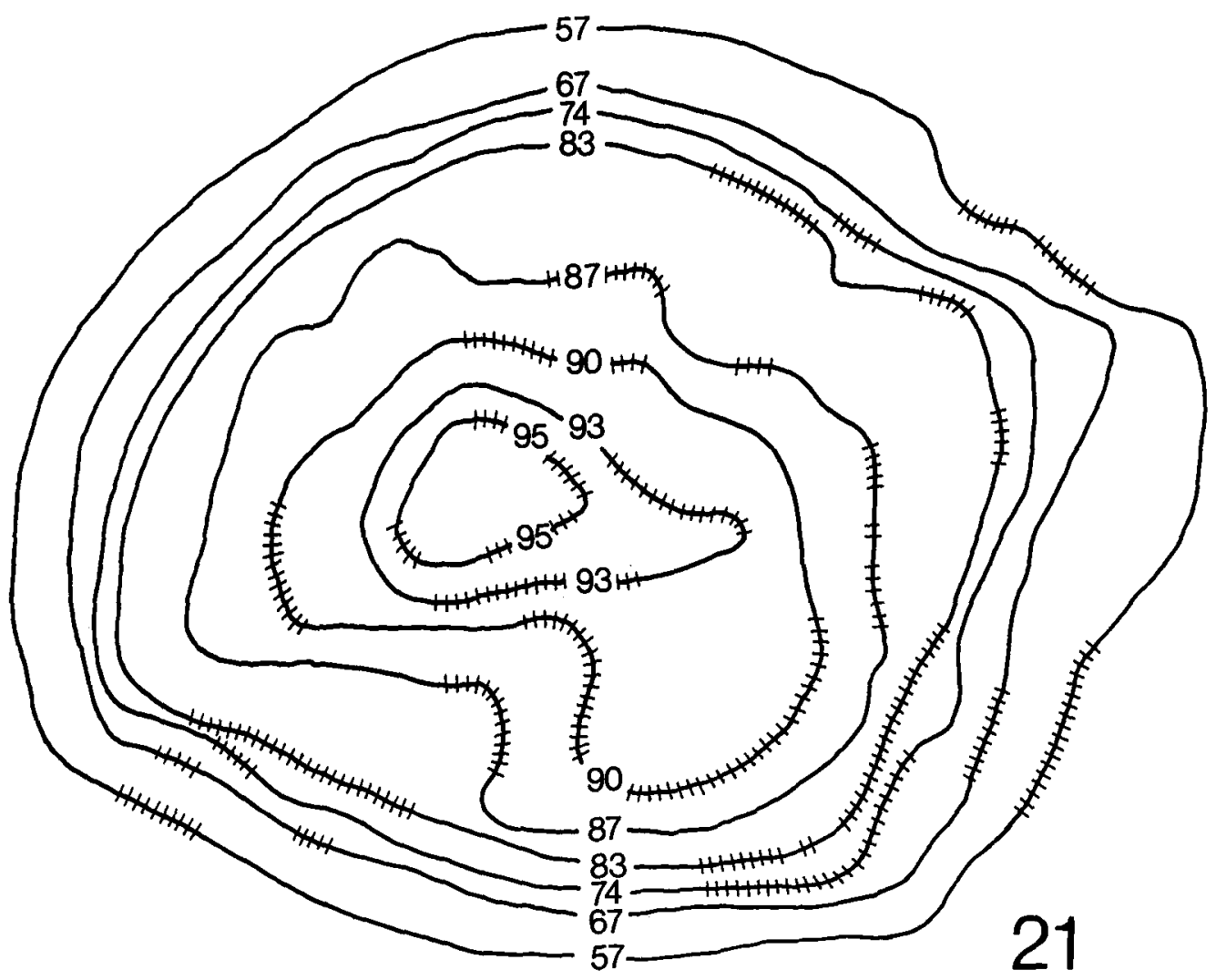

Figure 21. Nuclear pore locations (short, perpendicular lines) in second half of the same nucleus as in Fig. 18. Numbers are section numbers. $12,860 \times$

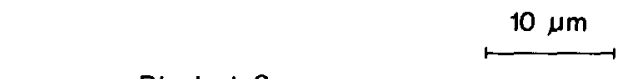

Bivalent 9
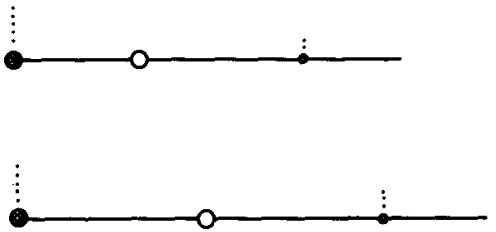

ơ

Bivalent 6

Figure 22. Idiogram of bivalents 9 and 6 comparing

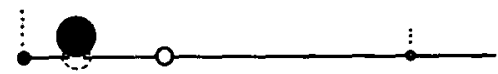
male and female nuclei. Lengths of the synaptonemal complexes were taken from the mean values of Tables I and II. Small circles. with dots represent knobs, open circles with solid line are centromeres, open circles with dotted line represent the nucleolus organizer. Large stippled circles are nucleoli.

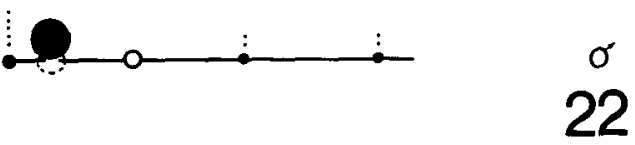


$10 \mathrm{~m}$ spicuous difference between the meiocytes observed in this study.

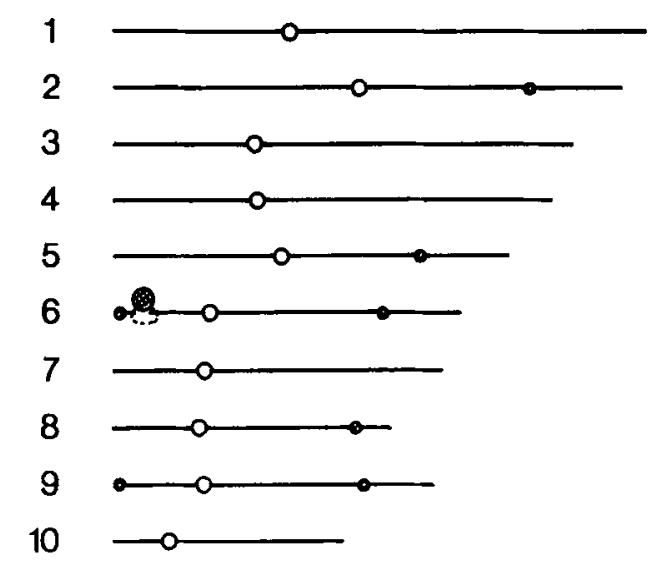

Figure 23. Idiogram based upon reconstruction of the synaptonemal complexes of the ten bivalents in female cell III of Tables I and II. Symbols are same as for Figure 22.

centromeres and interstitial knobs, centromere fusion, knob fusion, knob variability, and the mode and amount of telomere attachment to the nuclear membrane are all consistent features of both types of meiocyte.

The presence of a gap in the synaptonemal complex within the nucleolus organizer region of both microsporocytes and megasporocytes in the present study, and the absence of such a gap in the microsporocytes used by GILLIES (15) may indicate that the two studies were made on meiocytes at a slightly different stage. A synaptonemal complex gap has been reported in the nucleolus organizer region of Bombyx mori females (38), and in this species the gap was found to be present from late zygonema and to increase in length during pachynema (S. RASMUSSEN, personal communication). On the other hand, the close agreement of mean synaptonemal complex lengths for the total genome, for bivalent 6 , and for the long arm of bivalent 9 in all meiocytes of the two studies, points to a uniform length of the synaptonemal complexes during the different stages analyzed.

The absence of any large vacuoles within the nucleoli of megasporocytes is the most con-

\subsection{Chromosome length and crossing-over fre- quencies}

A positive correlation between bivalent length and the number of chiasmata has been determined by MATHER (29) for Drosophila melanogaster. Working with meiocytes in early diplonema to diakinesis this correlation has been substantiated in the locust, different grasshopper species and man $(14,21,25,45)$. In general, the correlation is taken to mean that greater bivalent length increases the chance for a chiasma to be formed. At least in the locust there is no indication of chiasma terminalization as observed with some other species (7) and the chiasma frequencies are therefore considered representative of crossover frequencies. The validity of the correlation also depends on the assumption that bivalent length at pachynema, at which stage crossingover is believed to occur $(17,22)$, corresponds to relative length at diplonema or diakinesis and thus that differential shortening among bivalents is absent. In a recent analysis of human meiosis Holm and RASMUSSEN (24) actually found that chiasma frequencies correlate better with the lengths of synaptonemal complexes than with bivalent lengths at diakinesis.

The proposal by Gillies et al. (19) that the greater cross-over frequency observed in the presence of the distinctly knobbed K10 chromosome in Zea mays is related to an increased length of the synaptonemal complex is supported by the results of the present study: In the presence of a terminal knob on the short arm of chromosome 9, the low female crossingover frequency in this arm is paralleled by a short synaptonemal complex and, conversely, the high male crossing-over frequency in the arm is paralleled by a long synaptonemal complex. The comparison has considerable weight since male and female meiocytes from the same plant were analyzed and the synaptonemal complex lengths of the long arms of chromosome 9 as well as the complex lengths of chromosomes 6 in the same nuclei did not reveal significant differences between the male 
and female side. The long arm of chromosome 9 and the chromosomes 6 thus provided an internal standard and make the observed difference independent of variations in bivalent length among nuclei as well as independent of possible length variations among different stages of pachynema.

The latter is defined at the electron microscopic level by the presence of a complete synaptonemal complex throughout the entire length of all bivalents (5). Constancy of total synaptonemal complex length in a nucleus during pachynema has been reported for maize $(15,17)$, Locusta (32), Bombyx (38), Sordaria (50) and human (24). In Drosophila melanogaster, synaptonemal complex lengths for two specific chromosomal regions were found to decrease during the first half of pachynema and to increase again towards the end of pachynema (3). A similar change in absolute total complex length from late zygonema to late pachynema is reported by MosES et al. for the autosomes of the Chinese hamster (33), but a constant relative synaptonemal complex length was established.

The analyses of RHOADES (42) reveals that influences of centromeric heterochromatin and heterochromatic knobs on crossing-over frequencies in maize frequently are limited to distinct chromosome segments, which is in agreement with the observation of a difference in synaptonemal complex length in a single chromosome arm as reported in this paper.

As pointed out no significant length differences could be established for bivalent 6 between male and female meiocytes. The actual values point to a somewhat greater length on the female side than on the male side. PHILlips $(36,37)$ has reported slightly higher cross-over frequencies for the female meiocytes in the $Y$. $\mathrm{su}_{2}$ interval of the long arm of chromosome 6 in three unrelated strains. The suggested connection between these two observations may, however, be fortuitous.

A positive correlation between synaptonemal complex length and crossing-over frequency may be viewed in the light of the preselection hypothesis of STERN, WESTERGAARD and vON WETTSTEIN (46). This hypothesis proposes that specific homologous stretches of DNA are preselected during early meiotic prophase prior to synapsis, and that these modified DNA stretches are susceptible to entrapment within the synaptonemal complex during its assembly. Subsequently, these DNA stretches offer potential sites for crossing-over via breakrepair mechanisms. While there is no evidence to indicate whether the amount of preselected DNA might determine synaptonemal complex length or vice versa, the longer the synaptonemal complex the greater the possibility for involvement of DNA within it.

\section{Table IV}

Summary of mean synaptonemal complex length, haploid DNA length, and chiasmata per nucleus for different organisms.

\begin{tabular}{l|c|c|c|c|c}
\hline & $\begin{array}{c}\text { Synaptonemal } \\
\text { complex } \\
\text { length } \\
(\mu \mathrm{m})\end{array}$ & $\begin{array}{c}\text { Haploid } \\
\text { DNA } \\
(\mathrm{mm})\end{array}$ & Chiasmata & $\begin{array}{c}\text { Synaptonemal } \\
\text { complex length } \\
\text { per haploid } \\
\text { DNA } \\
\%\end{array}$ & References \\
\hline Organism & 50 & 16 & 14 & 0.3 & $(15,47)$ \\
Neurospora & 110 & 61 & 5.6 & 0.2 & $(15,47)$ \\
Lilium & $3700^{*}$ & 60,000 & 29 & 0.006 & $(13,23)$ \\
Zea & 353 & 2,500 & $20-37$ & 0.015 & $(15,16)$ \\
Man & 231 & 2,300 & 52 & 0.01 & $(24,25)$ \\
Bombyx & 212 & 170 & 0 & 0.12 & $(38)$ \\
Chinese & 130 & 1,070 & - & 0.012 & $(33)$ \\
hamster & & & & \\
\hline
\end{tabular}

* zygotene lateral component length. 
Whereas thus synaptonemal complex length appears positively correlated with crossing-over frequencies within a single species, a comparison of different species reveals no obvious correlation between number of chiasmata and synaptonemal complex length or the ratio of synaptonemal complex length to length of DNA associated with it (Table IV). There is only a very weak correlation between amount of DNA and total synaptonemal complex length. It will be of interest whether in a given species changes in synaptonemal complex length can be induced by temperature, age and other agents known to affect the frequencies of crossing-over (49).

\subsection{Sex differences in crossing-over frequencies}

Besides complete suppression of crossingover in one sex such as in the male of Drosophila melanogaster $(6,30)$ or in the female of Bombyx mori (38) sex differences in crossing-over frequencies or chiasma frequencies have been observed in several plant and animal species $(13,27,42,47)$. RHOADEs (42) has recently reviewed the subject and shown that depending on the genotype and chromosome segment studied - the amount of crossing-over in male flowers of maize can be equal, higher or lower than in female flowers. Such information is also available for Primula (10) and the mouse (12). In maize higher cross-over values on the male than on the female side have been established in the centric heterochromatin region of chromosomes $3,4,5,7$, and $9(34,37,39,42)$. As mentioned above (42) the reverse situation is found for a region in chromosome $6(36,37)$. Equal values in male and female flowers are found in the short arm of chromosome 9 in the absence of the terminal heterochromatic knob (42), a slight reduction in the crossing-over frequency in the female flowers compared to the male flowers is obtained with a small terminal knob $(4,42)$ and a large reduction in the presence of the large knob (42). The present results indicate that different lengths of the synaptonemal complex in the short arm of chromosome 9 in female and male flowers are responsible for the sex difference in crossingover frequencies in this area. Preferential segregation of non-cross over chromatids into the functional megaspore as a cause for fewer cross-over individuals in the progeny (41) has been ruled out for a region in chromosome 5 by half tetrad analysis with diploid egg cells (35). It would be of interest to determine whether the sex difference in recombination frequencies in the centric heterochromatin segments in maize also is accompanied by a sex differential in the length of the synaptonemal complex. According to MikLos and NANKivell (31) heterochromatin is utilized in three species of Atractomorpha as a strategy to alter the frequency and positions of chiasmata, underscoring the importance of heterochromatization in the control of crossing-over.

FoGwILL (13) observed a higher female than male chiasma frequency in Lilium and Fritillaria. She suggested this to be attributable to an extended duration of meiotic prophase, chromosome coiling in the megasporocytes and to facilitated pairing in larger, less congested nuclei. FoGWILL (13) mentioned that the female bivalents are slightly larger than the male bivalents, but did not consider this a causal factor. Commenting on FogwILL's conclusions, JOHN and LEWIS (27) write "there is no reason to doubt that these differences apply also in those species where the female has a lower frequency than the male«. Generalizations among species on sex differences in chiasma frequency, duration of meiosis or nuclear size are hardly tenable. For instance chiasma frequencies in Hordeum vulgare do not differ between micro and megasporocytes and duration of male and female meiosis is very similar (2). From the present study in maize, the nuclear size can be estimated from the number of sections required to pass through a nucleus (Tables I and II). The average of the five nuclei in the male meiocytes of $16.0 \mu \mathrm{m}$ is slightly larger than the average of $14.5 \mu \mathrm{m}$ for the five female nuclei.

\section{ACKNOWLEDGEMENTS}

I am indebted to professor D. voN WETTSTEIN for suggesting this project and for his critical review of the manuscript. Thanks are extended to professor M. M. RHOADEs for generously providing the stocks, helpful advice 
and unpublished information and to Drs. Preben Holm, Søren Rasmussen, and David SIMPSON for very valuable discussions. Outstanding technical assistance by JEAN SAGE, Ann-Sofi Steinholtz, ShiRley Mogensen and NINA RASMUSSEN is gratefully acknowledged. The work was supported in part by grant GM-22051 of the National Institutes of Health, U.S. Public Health Service to professor D. von WetTSTEIN.

\section{REFERENCES}

1. Bennett, M. D.: Time and duration of meiosis. Phil. Trans. R. Soc. Lond. B. 227, 201-226 (1977)

2. Bennett, M. D., R. A. Finch, J. B. SMith \& M. $K$. RAO: The time and duration of female meiosis in wheat, rye and barley. Proc. R. Soc. Lond. B. 183, 301-319 (1973)

3. Carpenter, A. T. C.: Electron microscopy of meiosis in Drosophila melanogaster females. I. Structure, arrangement and temporal change of the synaptonemal complex in wild-type. Chromosoma (Berl.) 51, 157-182 (1975)

4. Chang, C. C. \& G. Y. KIKudome: The interaction of knobs and $B$ chromosomes of maize in determining the level of recombination. Genetics 77, 45-54 (1974)

5. Comings, D. E. \& T. A. OKaDA: Architecture of meiotic cells and mechanisms of chromosome pairing. Adv. Cell \& Mol. Biol. 2, 310-384 (1972)

6. Darlington, C. D.: The origin and behaviour of chiasmata, VII. Zea mays. Z. Vererblehre 67, 96114 (1934)

7. Darlington, C. D.: Recent advances in cytology. 2nd ed. Churchill, London (1937)

8. Davies, E. D. G. \& G. H. Jones: Chiasma variation and control in pollen mother cells and embryo-sac mother cells of rye. Genet. Res., Camb. 23, 185-190(1974)

9. DAvis, G. L.: Systematic embryology of the angiosperms. John Wiley and Sons, Inc., New York (1966)

10. De Winton, D. \& J. B. S. Haldane: The genetics of Primula sinensis. III. Linkage in the diploid. J. Genetics 31, 67-100(1935)

11. Dickinson, H. G. \& J. Heslop-Harrison: Ribosomes, membranes and organelles during meiosis in angiosperms. Phil. Trans. R. Soc. Lond. B. 227, 327-342 (1977)

12. Dunn, L. C. \& D. BennetT: Sex differences in recombinations of linked genes in animals. Genet. Res. 9, 211-220 (1967)
13. FoGWILl, MARY: Differences in crossing-over and chromosome size in the sex cells of Lilium and Fritillaria. Chromosoma (Berl.), Bd. 9, 5, 493-504 (1958)

14. Fox, D. P.: The control of chiasma distribution in the locust, Schistocerca gregaria (Forskål). Chromosoma (Berl.) 43, 289-328 (1973)

15. Gillies, C. B.: Ultrastructural analysis of maize pachytene karyotypes by three dimensional reconstruction of the synaptonemal complexes. Chromosoma 43, 145-176 (1973)

16. Gillies, C. B:: An ultrastructural analysis of chromosome pairing in maize. C. R. Trav. Lab. Carlsberg 40, 135-161 (1975a)

17. Gillies, C. B.: Synaptonemal complex and chromosome structure. Ann. Rev. Genet. 9, 91109 (1975b)

18. Gillies, C. B. \& B. B. Hyde: Intranucleolar bodies in maize pachytene microsporocytes. Hereditas 74, 137-140(1973)

19. Gillies, C. B., S. W. Rasmussen \& D. voh WETTSTEIN: The synaptinemal complex in homologous and non-homologous pairing of chromosomes. Cold Spring Harbor Symp. Quant. Biol. 38, 117-122 (1973)

20. GRIM, J. N.: Ultrastructure of pellicular and ciliary structures of Euplotes eurystomus. J. Protozool. 14, 625-634 (1967)

21. Henderson, S. A.: Chiasma distribution at diplotene in a locust. Heridity 18, 173-190 (1963)

22. Henderson, S. A.: The time and place of crossing-over. Ann. Rev. Genet. 4, 295-324 (1970)

23. Holm, P. B.: Three-dimensional reconstruction of chromosome pairing during the zygotene stage of meiosis in Lilium longiflorum (Thunb.). Carlsberg Res. Commun. 42, 249-281 (1977)

24. Holm, P. B. \& S. W. Rasmussen: Human meiosis I. The human pachytene karyotype analyzed by three dimensional reconstruction of the synaptonemal complex. Carlsberg Res. Commun. 42, 283-323 (1977)

25. Hultén, M.: Chiasma distribution at diakinesis in the normal human male. Hereditas 76, 55-78 (1974)

26. Israel, H. W. \& T. Sagawa: Post pollination ovule development in Dendrobium orchids. III. Fine structure of meiotic prophase I. Caryologia $18,15-34$ (1965)

27. John, B. \& K. R. LewIS: The meiotic system. Protoplasmatologia VI, 3-331 (1965)

28. KIESSELBACH, T. A.: The structure and reproduction of corn. Univ. of Neb. Coll. Agr. Exp. Sta. Res. Bul. 61 (1949)

29. MAther, K.: The determination of position in crossing-over. II. The chromosome length - 
chiasma frequency relation. Cytologia Fujii Jub. Vol., 514-526 (1937)

30. LindSLEY, D. L. \& L. SANDLER: The genetic analysis of meiosis in female Drosophila melanogaster. Phil. Trans. R. Soc. Lond. B. 277, 183-376 (1977)

31. Miklos, G. L. G. \& R. NANKivell: Telomeric satellite DNA functions in regulating recombination. Chromosoma (Berl.) 56, 143-167 (1976)

32. MoENS, P. B.: Quantitative electron microscopy of chromosome organization at meiotic prophase. Cold Spr. Harb. Symp. Quant. Biol. 38, 99-107 (1973)

33. Moses, M. J., G. H. Slatton, T. M. Gambling \& C. F. Starmer: Synaptonemal complex karyotyping in spermatocytes of the Chinese hamster (Cricetalus griseus). Chromosoma (Berl.) 60, 345-375 (1977)

34. NEL, P. M.: The modification of crossing-over in maize by extraneous chromosomal elements. Theor. Appl. Genet. 43, 196-202 (1973)

35. NEL, P. M.: Crossing-over and diploid egg formation in the elongate mutant of maize. Genetics 79, 435-450(1975)

36. Phillips, R. L.: Recombination in Zea mays L. II. Cytogenetic studies of recombination in reciprocal crosses. Genetics 61, 117-127 (1969)

37. PhilliPs, R. L.: A chormosome region with more crossing-over in megasporogenesis than in microsporogenesis. Maize Genet. Crop. News Letter 45, 123-125 (1971)

38. Rasmussen, S. W.: The meiotic prophase in Bombyx mori females analyzed by three dimensional reconstructions of synaptonemal complexes. Chromosoma (Berl.) 54, 245-293 (1976)

39. RHOADES, M. M.: Different rates of crossing-over in male and female gametes of maize. J. Amer. Soc. Agron. 33, 603-615 (1941)
40. RhoAdes, M. M.: Meiosis in maize. J. of Heredity 41, 59-67 (1950)

41. Rhondes, M. M.: The cytogenetics of maize. In Corn and Corn Improvement. Ed. G. F. Sprogne. Academic Press. Chap. IV (1955)

42. RHOADES, M. M.: The genetic effects of heterochromatin in maize In: Proc. of the Internat. Maize Symposium: Genetics and Breeding. Ed. D. B. Walden. Wiley-Interscience New York (1978)

43. RoDkiewicz, B. \& E. Mikulska: The development of cytoplasmic structures in the embryo sac of Lillium candidum, as observed with the electron microscope. Planta 67, 297-304 (1965)

44. SHERIDAN, W. F. \& R. J. BarnetT: Cytochemical studies on chromosome ultrastructure. J. Ultrastruct. Res. 27, 216-229 (1969)

45. Southern, D. I.: Chiasma distribution in truxaline grasshoppers. Chromosoma 22, 164-191 (1967)

46. Stern, H., M. WestergaArd \& D. von WetTStEIN: Presynaptic events in meiocytes of Lilium logiflorum and their relation to crossingover: A preselection hypothesis. Proc. Nat. Acad. Sci. 72, 961-965(1975)

47. Vosa, C. G.: Two track heredity: Differentiation of male and female meiosis in Tulbaghia. Caryologia 25, 275-281 (1972)

48. WestergaARd, M. \& D. von Wettstein: The synaptinemal complex. Ann. Rev. Genet. 6, 71 $110(1972)$

49. Whitehouse, H. L. K.: Towards an understanding of the mechanism of heredity. Edward Arnold Ltd., London (1973)

50. ZiCKL.ER, D.: Development of the synaptonemal complex and the "recombination nodule during meiotic prophase in the seven different bivalents og the fungus Sordaria macrospora Auersw. Chromosoma (Berl.) 61, 289-316 (1977) 